\title{
Effect of Tianeptine on Glucose Tolerance with Insulin Secretion in Human: Potential Anti-Diabetic Effect of the Drug
}

\author{
Fuad Lechin ${ }^{*}, 1$, Bertha van der Dijs ${ }^{1}$, Betty Pardey Maldonado ${ }^{1}$, Scarlet Baez and Marcel E. Lechin ${ }^{2}$ \\ ${ }^{I}$ Department of Physiological Sciences, Sections of Neuroendocrinology, Neuropharmacology, and Neurochemistry, \\ Instituto de Medicina Experimental, Faculty of Medicine, Universidad Central de Venezuela, Caracas, Venezuela \\ ${ }^{2}$ Department of Internal Medicine, Texas A \& M Health Science Center, College of Medicine, Texas, USA
}

\begin{abstract}
Due to the fact that drugs which interfere with the serotonin (5-HT) uptake (doxepin, sertraline, fluvoxamine and fluoxetine), were able to minimize the insulin release from islet beta-cells and counteract hypoglycemia, we investigated the effects of tianeptine, a drug which enhances 5-HT uptake during the oral glucose tolerance test. We found that the drug triggered significant and sustained insulin rises which were opposite to the plasma glucose decreases. The fact that significant noradrenaline/adrenaline (NA/Ad) plasma ratio paralleled insulin rises throughout the test is consistent with the excitatory role played by the peripheral neural sympathetic activity. Additionally, the positive correlations registered between NA versus DA (dopamine) plasma levels indicate that the latter arose from sympathetic nerves rather than the adrenal glands. Furthermore, the significant reductions of both platelet and plasma 5-HT registered throughout the OGTT plus tianeptine test support the postulation that reduction of the parasympathetic drives is occurring. This parasympathetic drive is responsible for the secretion of 5-HT from the enterochromaffin cells. Finally, considering that circulating 5-HT excites alpha-cells and modulates beta-cells, it is possible to infer that minimization of this factor contributed to the insulinogenic effect displayed by the association of this drug to an oral glucose load. We also discussed the peripheral and central nervous system mechanisms responsible for the insulinogenic effect registered throughout the test.
\end{abstract}

Keywords: Diabetes, hyperinsulinism, neural sympathetic activity, serotonin, tianeptine.

\section{INTRODUCTION}

The concept of "entero-insular axis" began in 1962 when we demonstrated that the gastrointestinal (GI) hormone secretin was found to be able to excite the release of not only the pancreatic exocrine secretion but also the endocrine (insular) activity [1-3]. It was demonstrated that this gastrointestinal factor acted at the beta-cell level. In addition, it was also found that another gastrointestinal factor, serotonin (5-HT), was able to inhibit the insulin release in vitro $[4,5]$. The above findings were further ratified by multiple research studies [6,7]. Furthermore, whereas intraportal infusion of serotonin was able to inhibit the stimulated insulin secretion in dogs [5], insulin (subcutaneously injected) was able to elevate platelet serotonin (p5-HT) circulating levels in essential hypertensive patients but not in non-essential hypertensive or normal subjects [7]. This phenomenon was attributed to the hyperactivity of neural sympathetic system plus the hypoactivity of the adrenal glands secretion always observed in the essential hypertensive subjects. Moreover, many studies carried out by other researchers ratified our preliminary findings and even showed that not only serotonin but other GI factors were also able to control the secretion of insulin by beta cells [8]. The above information has been quoted in our review article discussing hyperinsulinism [9].

*Address correspondence to this author at the Apartado 80.983, Caracas 1080-A, Venezuela; Fax: +58 212961 0172; E-mail: flechin@telcel.net.ve
Other research studies carried out in our department demonstrated that the experimentally-induced depression (captivity) was able to provoke a diabetogenic effect in dogs [10]. The fact that these dogs showed greatly increased $\mathrm{p} 5$ HT, and that in addition normalization of the OGTT plus p5HT levels paralleled both the disappearance of the psychological disorder as well as the diabetic syndrome; led us to postulate that serotonin played a primary role in the inhibition of the islet beta-cells [11,12]. Furthermore, we also demonstrated that the chronic administration of some dopaminergic (DA) blocking agents like sulpiride, were able to provoke a diabetogenic effect plus a p5-HT elevation similar to that registered during captivity [11]. Evenmore, the fact that normalization of clinical, hormonal and glucose parameters was observed after the interruption of drug administration allowed us to postulate that serotonin was the common etiopathogenic factor responsible for both the metabolic and the psychiatric disorder [13]. The above findings were furtherly confirmed and published $[9,14,15]$. Finally, our demonstration dealing with the annulment by doxepin (a serotonin uptake inhibitor) of the hyperinsulinism plus hypoglycemia syndrome, affecting a great bulk of patients [16] led us to assess the possible insulinogenic effect of drugs like tianeptine which enhances rather than inhibits the uptake of 5-HT [17].

\section{MATERIALS AND METHODOLOGY}

One OGTT plus placebo and one OGTT plus tianeptine test were carried out 2 weeks apart in 48 caucasic normal voluntary humans ( 26 males and 22 females), whose ages 
ranged from 20 to 63 years (Mean \pm s.e.m. $=42.6 \pm 5.8)$. All of them gave informed written consent and the procedure was approved by the ethical committee of FUNDAIME. All subjects were within $10 \%$ of ideal body weight, and none had undergone abdominal surgery or were taking any medications. None of the subjects had physical or psychiatric illness. Subjects were rated on a modified Hamilton Depression Rating Scale for Depression and all of them completed the self-rating Beck Depression Inventory [16] in order to discard subjects with depression. Pregnancy, lactation, smoking and/or alcoholism also excluded subjects.

\section{Analytical Methods}

Noradrenaline (NA), adrenaline (Ad), dopamine (DA), plasma free serotonin (f5-HT), platelet serotonin ( $\mathrm{p} 5-\mathrm{HT}$ ), glucose and insulin were measured throughout the 180 minute testing period. For all parameters, the samples were assayed in duplicate and all determinations were made simultaneously. We used reverse-phase, ion-pair high performance liquid chromatography with electrochemical detection for the detection of monoamines. Optimization of chromatographic conditions and attainment of adequate quantification parameters allowed us to maximize sensitivity and reproducibility.

All tests were performed on recumbent subjects, after 14 hours of fastening. A heparinized venous catheter was inserted into a forearm vein at least $30 \mathrm{~min}$ before beginning the tests. Blood samples were collected at 0, 60, 90, 120 and 180 minutes. Each subject drank a 30\% glucose solution (1 $\mathrm{gm} / \mathrm{kg}$ of ideal body weight) plus placebo or an oral dose of tianeptine $(12.5 \mathrm{mg}=$ one tablet). Blood for catecholamines and serotonin assays was transferred to plastic tubes, each containing $20 \mathrm{mg}$ of EDTA plus $10 \mathrm{mg}$ of sodium bisulfite $/ \mathrm{ml}$ of solution. The tubes were carefully inverted and placed on ice. The blood was promptly centrifuged at $600 \mathrm{rpm}$ for $15 \mathrm{~min}$ at $4^{\circ} \mathrm{C}$ in order to obtain platelet-rich plasma. Two milliliters of platelet-rich plasma, obtained for determination of platelet serotonin (p5-HT), were taken and stored at $-70{ }^{\circ} \mathrm{C}$ until assayed. The remaining blood was again centrifuged at 7,000 rpm. The supernatant, plateletpoor plasma, was divided into two portions for determination of catecholamines and f5-HT, after which both portions were stored at $-70^{\circ} \mathrm{C}$ until assayed.

A physician in constant attendance noted any symptoms reported by the subjects and monitored heart rate, systolic blood pressure and diastolic blood pressure every 30 minutes.

\section{Reagents and Standards}

Noradrenaline, adrenaline, dopamine, serotonin creatinine sulphate, dihydroxybenzylamine, sodium octyl sulphate, dibutylamine, acid-washed aluminium oxide, $\mathrm{Na} 2 \mathrm{HPO} 4$, citric acid and EDTA were purchased from Sigma-Aldrich (St Louis, MO, USA). Microfilters were purchased from Whatman Inc. (Florham Park, NY, USA) through Merck S.A, (Caracas, Venezuela). Acetonitrile and 2-propanol were obtained from Merck, S.A. (Caracas, Venezuela). Glass-distilled water was de-ionized and filtered through a Milli-Q reagent grade water system (Millipore, Bedford, MA, USA). Solvents were filtered through a 0.2 $\mu \mathrm{m}$ Millipore filter and were vacuum deaereated. Standard solutions $(1 \mathrm{mmo} 1 / 1)$ were prepared in $0.1 \mathrm{mo} 1 / 1$ perchloric acid and diluted to the desired concentration.

\section{Equipment}

Liquid chromatography was performed using Waters 515 HPLC pump (Waters Corporation, Milford, Massachusetts. USA) equipped with a Rheodyne valve injector $7125 \mathrm{i}$, which was fitted with a $50 \mu 1$ sample loop (Rheodyne; Berodine, Berkeley, CA, USA). A $15 \mathrm{~cm} \mathrm{x} 4.6 \mathrm{~mm}$ inner diameter Discovery C18 column packed with octadecylsilane $5 \mu \mathrm{m}$ particles was preceded by a column prefilter of $2 \mu \mathrm{m}$ porosity, both from Supelco/Sigma-Aldrich (Sigma-Aldrich, St. Louis, MO, USA). The detection system was a Waters 460 Electrochemical Detector (Waters Corporation, Milford, MA, USA). The potential of the working electrode (glass carbon) was set at $+0.61 \mathrm{~V}$ versus the $\mathrm{Ag}-\mathrm{AgCl}$ reference electrode for the detection of catecholamines and $0.70 \mathrm{~V}$ versus the $\mathrm{Ag}-\mathrm{AgCl}$ for the detection of indoleamines. The chromatograms were registered and quantified with the Empower software from Waters Corp. The results were corrected for the volume of EDTA added.

\section{Analytical Assays}

Plasma catecholamines. The assay was performed by extraction of the catecholamines onto $20 \mathrm{mg}$ of alumina followed by their elution with $200 \mu 1$ of $1.0 \mathrm{mo} 1 / \mathrm{L} \mathrm{HClO}_{4}$ using Regenerated Cellulose microfilters $0.2 \mu \mathrm{m}$ pore size (Whatman Inc). We calibrated the instrument with standard plasma: after incubation with acid-washed aluminum oxide, a plasma pool of free catecholamines was processed similarly to plasma samples, but $20 \mu \mathrm{l}$ of a standard solution of NA, Ad and DA (50, 25 and $25 \mathrm{ng} / \mathrm{ml}$, respectively) were added to the plasma pool. Both the standard plasma and the sample plasma were supplemented with $20 \mu 1$ of internal standard (100 ng/ml of dihydroxybenzylamine). The mobile phase was $\mathrm{KH}_{2} \mathrm{PO}_{4} 6.8045 \mathrm{~g} / \mathrm{L}$, EDTA $0.100 \mathrm{gm} / \mathrm{L}$ and di-Nbutylamine $100 \mu \mathrm{l} / \mathrm{L}$. Sodium octyl sulphate was added as ion-pair agent in a concentration of $0.6125 \mathrm{~g} / \mathrm{L}$ with the $\mathrm{pH}$ adjusted to 5.6. The sensitivity of this method for NA, Ad and DA was $6.4,5.8$ and $2.0 \mathrm{pg} / \mathrm{ml}$, respectively. The intraassay coefficients of variation were $2.8,4.0$ and $4.0 \%$, respectively. The inter-assay coefficients of variation were $6.7,4.5$ and $4.3 \%$, respectively.

Plasma indoleamines. After sonication of platelet-rich plasma to disrupt the platelets (Ultrasonic Liquid Processor, model 385; Heat Systems Ultrasonics Inc., Farmingdale, NY, USA), both platelet-rich and platelet-poor plasma were processed in the same way: $200 \mu 1$ of $3.4 \mathrm{~mol} / \mathrm{L}$ perchloric acid and $50 \mu 1$ of 5-hydroxy-tryptophan solution (114.5 $\mu \mathrm{g} / \mathrm{ml}$ ) as internal standard, were added to $1 \mathrm{ml}$ of plasma vortexed and centrifuged at $10,000 \mathrm{rpm}$ for $15 \mathrm{~min}$ at $4^{\circ} \mathrm{C}$. The supernatant was filtered through a $0.22 \mu \mathrm{m}$ membrane (Millipore) and $10 \mu 1$ was injected into the column. Calibration runs were generated by spiking blank plateletpoor plasma with $50 \mu 1$ of a solution containing 5-HT (10 $\mu \mathrm{g} / \mathrm{ml})$ and $50 \mu \mathrm{l}$ of 5-hydroxy-tryptophan $(114.5 \mu \mathrm{g} / \mathrm{ml})$. This standard plasma was processed in the same manner as the samples. The mobile phase was citric acid $3.8424 \mathrm{gr} / \mathrm{L}$, sodium acetate $4.1015 \mathrm{gr} / \mathrm{L}$, EDTA $0.100 \mathrm{gr} / \mathrm{L}$, di-Nbutylamine $100 \mu \mathrm{l} / \mathrm{L}$ and $30 \mathrm{ml} / \mathrm{L}$ of 2-propanol. Sodium octyl sulphate was added as ion-pair agent in a concentration of $4.25 \mathrm{mg} / \mathrm{L}$ with a $\mathrm{pH}$ of 5.0 . The sensitivity of the method 

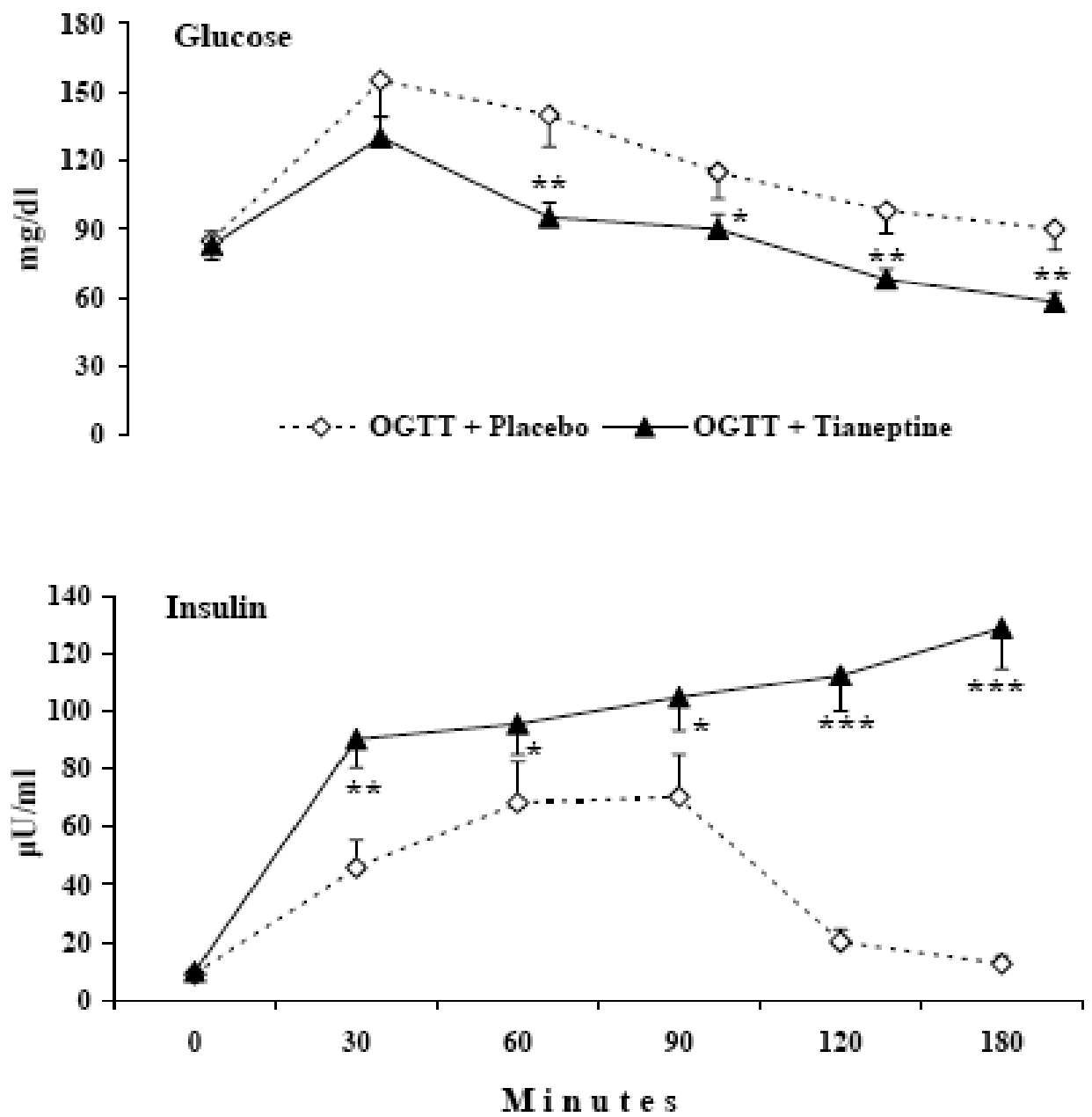

Fig. (1). The addition of tianeptine to an oral glucose load potentiated both the insulin rises plus its hypoglycemic effects normally registered throughout this test without the drug. $(\mathrm{n}=48)$ Values are expressed as mean \pm s.e.m. $\left(^{*}\right) p<0.05 ;(* *) p<0.02 ;(* * *) p<0.01(\mathrm{OGTT}+$ Tianeptine versus OGTT + Placebo).

for serotonin was $0.1 \mathrm{ng} / \mathrm{ml}$. The intra-assay coefficients of variation for p5-HT and f5-HT were 6.2 and $8.7 \%$, respectively.

Plasma insulin. This was determined by a radioimmunoassay with an insulin-antibody precipitate [16].

Plasma glucose. The levels of plasma glucose were estimated by enzyme-linked method in an auto chemistry analyzer (Rayto, model 1904C, Rayto Life and Analytical Sciences, Chine).

\section{Statistical Methods}

Results are expressed as mean \pm SE. Multivariate analysis of variance with repeated measurements, paired $t$ test, and correlation coefficients (exploratory factor analysis) were used; $p<0.05$ was considered significant. Dbase Stats (TM) by Ashton Tate and Statview SE + Graphics by Abacus were used for statistical analyses.

\section{RESULTS}

\section{Oral Glucose + Placebo Test}

The assessment of circulating neurotransmitters after an oral glucose load carried out according to the present protocol ratified other previously published research studies
[18]. Only NA and p5-HT circulating values showed significant and sustained rises that paralleled insulin increases and opposed plasma glucose reductions. In addition, Ad and DA showed significant decreases at the 90min, 120, and 180min periods. All subjects fell asleep and displayed rapid eye movements (REM) during the test. Maximal rise of glucose was registered at the $30 \mathrm{~min}$ period, whereas minimal mean values were reached at the $180 \mathrm{~min}$ period. In addition to the above, although both NA and p5HT levels were raised after the oral glucose load, the NA/p5HT ratio showed significant decreases throughout the OGTT.

All subjects showed a normal OGTT. Normal rises of glucose and insulin were registered throughout the test (Fig. 1). Aside from glucose rise, significant increases in NA (Fig. 2), NA/Ad (Fig. 3), and p5-HT (Fig. 4) were registered. Significant reduction of Ad values were registered throughout the test. No significant changes were observed in DA and f5-HT. Slight but significant decreases of heart rate and systolic blood pressure (SBP) mean + s.e.m. values were registered throughout the test. Significant reductions in the NA/p5-HT (Fig. 3), Ad/p5-HT and DA/p5-HT ratios mean values were also registered at 60, 90, 120 and 180min (Fig. 5). All of our subjects fell asleep and displayed REM during 

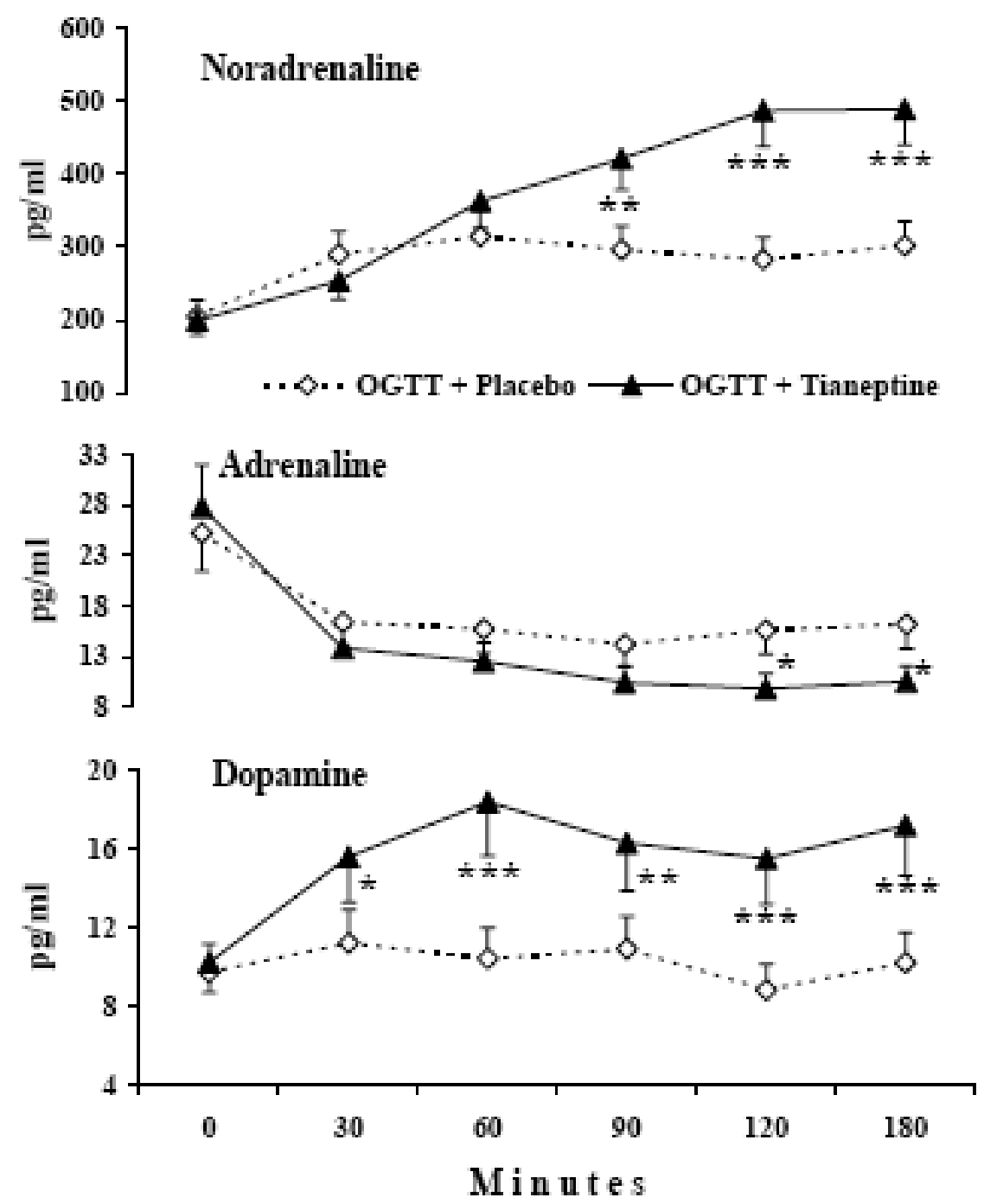

Fig. (2). The addition of tianeptine to an oral glucose load potentiated the normal NA and DA rises (neural sympathetic activity) as well as the decreases of Ad (adrenal sympathetic activity), always registered troughout this test without the drug. $(\mathrm{n}=48)$ Values are expressed as mean \pm s.e.m. $(*) p<0.05 ;(* *) p<0.02 ;(* * *) p<0.01$ (OGTT + Tianeptine versus OGTT + Placebo).

OGTT, especially accentuated at these same periods (90 and 180min). Correlations are in Table 1.

\section{Oral Glucose + Tianeptine Test}

Subjects did not show drowsiness throughout the test. This fact, in contraposition with the other one occurred in the glucose challenge alone, may be associated with the decreased circulating levels of serotonin observed with the addition of tianeptine. The potentiation of insulin secretion triggered by a small dose of oral tianeptine when added to an oral glucose dose (Fig. 1), should be associated with the changes of the autonomic nervous system parameters registered in this study, namely, the increase of both NA and DA plus the decreases of Ad (Fig. 2), p5-HT and f5-HT circulating levels (Fig. 4). With respect to this, we will discuss the possible physiological and pharmacological mechanisms underlying the above findings.

\section{Plasma Catecholamine Changes}

The close positive correlations registered between NA and NA/Ad ratio when these parameters were plotted versus
DA strongly suggest that the latter arose from the sympathetic nerves rather than the adrenal glands (Table 2). Furthermore, the significant positive correlations registered between NA and DA versus diastolic blood pressure (DBP), but not versus SBP and heart rate (Table 3 ), indicates that neural not adrenal sympathetic activity was responsible for these changes.

\section{Circulating Indolamine Changes}

The significant reductions of both $\mathrm{p} 5$-HT and f5-HT indicate that the normal post-glucose enhancement of these indoleamines was reversed by the drug (Fig. 4). No significant correlations were found between these parameters when plotted against catecholamines before or after the administration of the glucose load.

\section{Plasma Glucose Changes}

Small but significant rise of glucose levels were registered at the $30 \mathrm{~min}$ and $60 \mathrm{~min}$ post-glucose periods. Non significant increases were found at the $90 \mathrm{~min}, 120 \mathrm{~min}$ and 180min post-glucose periods (Fig. 1). 

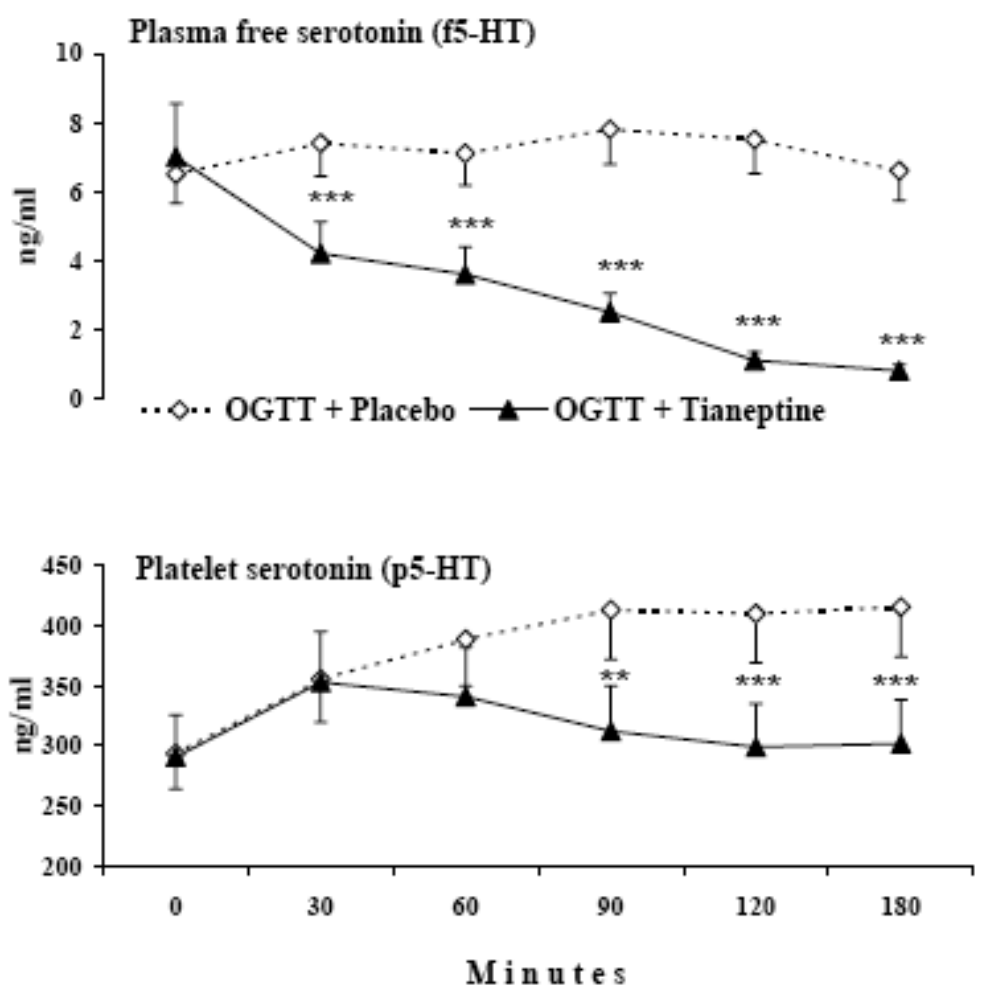

Fig. (3). The addition of tianeptine to an oral glucose load reversed the plasma serotonin (f5-HT) and platelet serotonin (p5-HT) rises, normally registered troughout this test without the drug. $(\mathrm{n}=48)$ Values are expressed as mean \pm s.e.m. $(* *) p<0.02 ;(* * *) p<0.01(\mathrm{OGTT}+$ Tianeptine versus OGTT + Placebo).
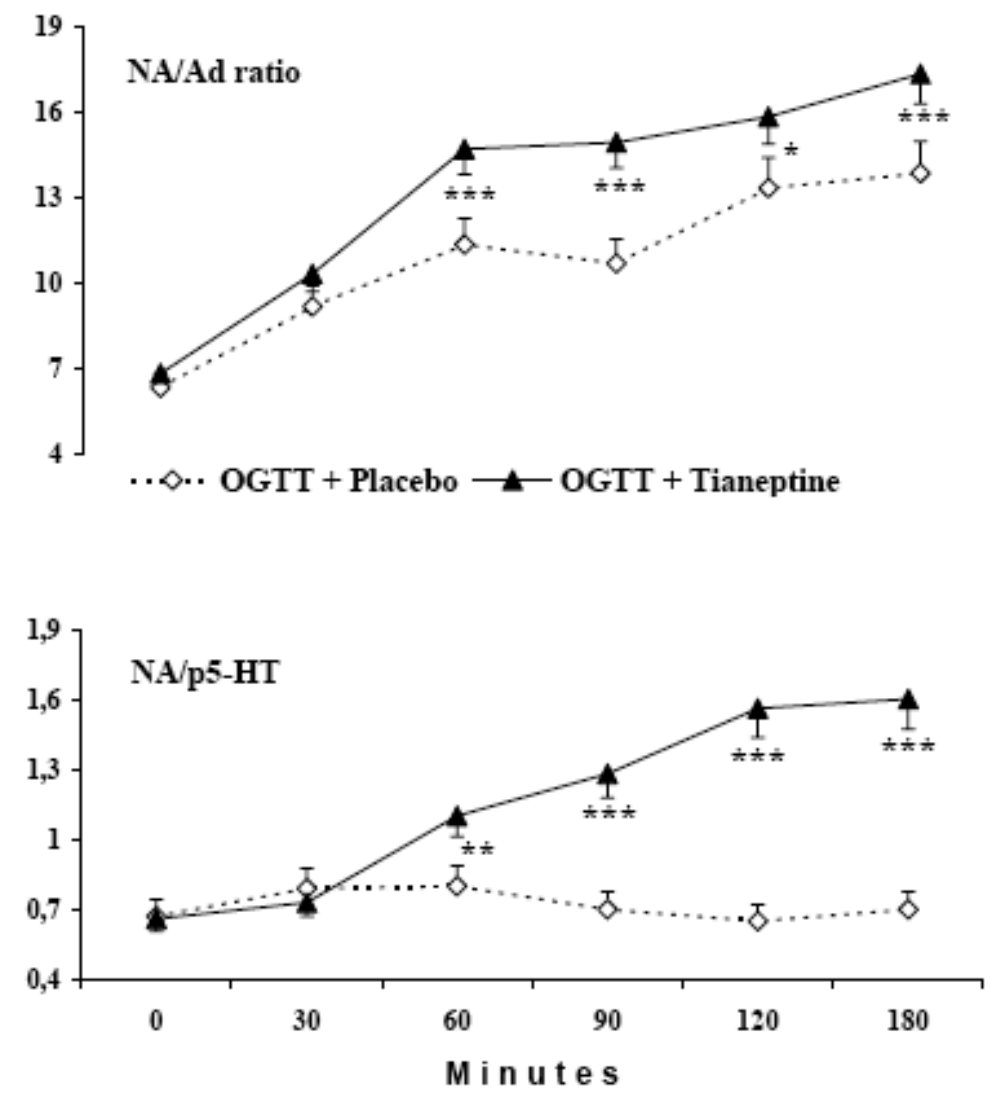

Fig. (4). The addition of tianeptine to an oral glucose load potentiated the normal NA/Ad ratio registered throughout this test without the drug. It also provoked the enhancement of the NA/p5-HT ratio triggered by both the NA rises and the p5-HT fall. (n $=48$ ) Values are expressed as mean \pm s.e.m. $(*) p<0.05 ;(* *) p<0.02 ;(* * *) p<0.01$ (OGTT + Tianeptine versus OGTT + Placebo). 

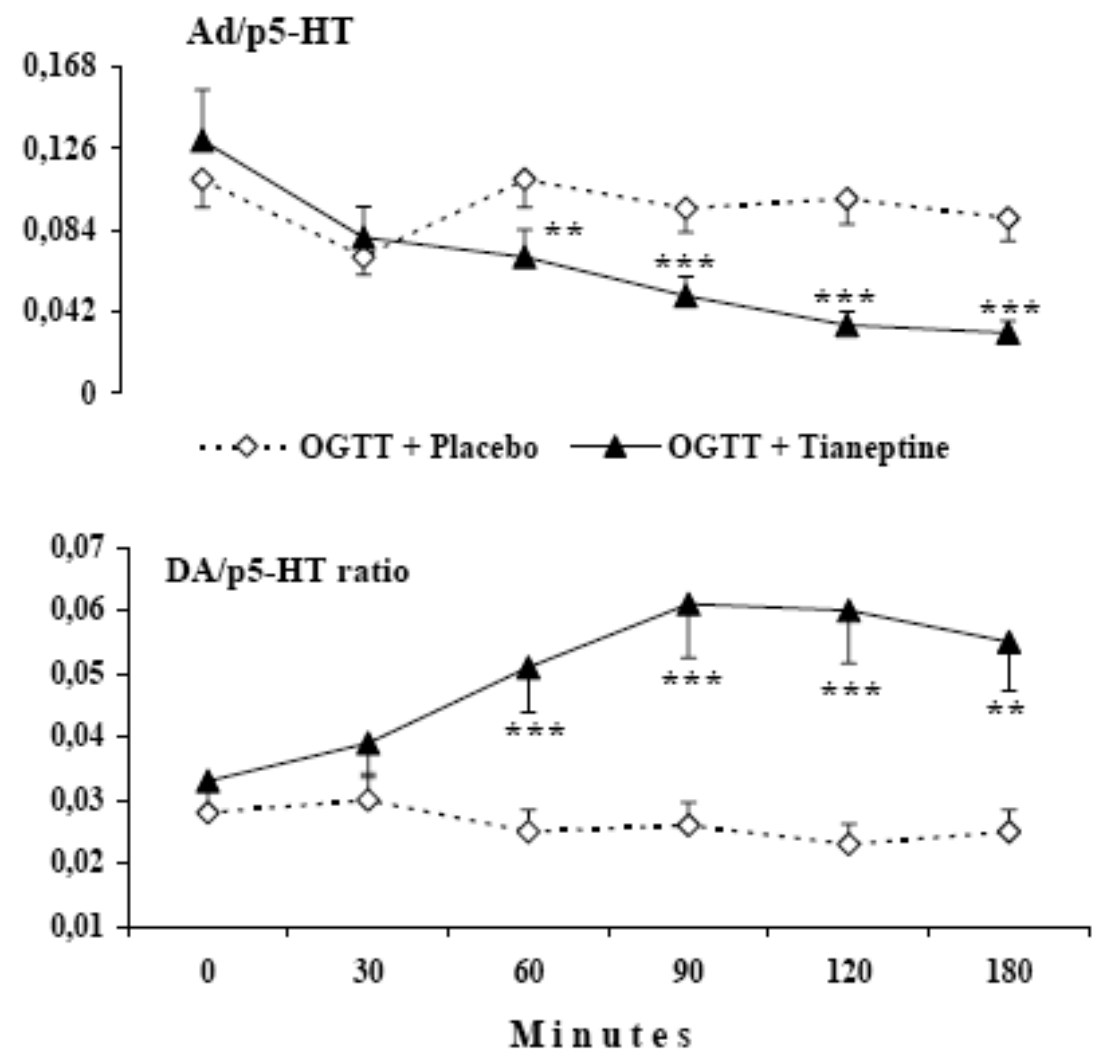

Fig. (5). The addition of tianeptine to an oral glucose load triggered the fall of both adrenaline (Ad) and platelet serotonin (p5-HT) as well as the $\mathrm{Ad} / \mathrm{p} 5$-HT ratio. In addition, significant increases of the DA/p5-HT ratio were observed. $(\mathrm{n}=48)$ Values are expressed as mean \pm s.e.m. $(* *) p<0.02 ;(* * *) p<0.01$ (OGTT + Tianeptine versus OGTT + Placebo).

\section{lasma Insulin Changes}

Significant, progressive and sustained insulin rises were registered starting with the first $30 \mathrm{~min}$ period until the final 180 min period (Fig. 1).

\section{Correlations}

Significant positive correlations were noted between NA versus DA; NA/Ad versus DA; NA/Ad versus DBP; NA versus insulin; NA/Ad versus insulin; and DA versus insulin at the $60 \mathrm{~min}, 90 \mathrm{~min} 120 \mathrm{~min}$ and $180 \mathrm{~min}$ periods. Significant negative correlations were found between DA versus DBP at the last four periods (Table 2).

\section{DISCUSSION}

The potentiation of the insulin secretion triggered by the addition of a small dose of tianeptine to an oral glucose load should be associated with the enhancement of neural sympathetic activity registered in this study as inferred from the close positive and negative correlations we found between NA versus DA and NA versus Ad, respectively, as well as from the significant positive correlations demonstrated between NA versus insulin and DA versus insulin. Conversely, significant negative NA versus p5-HT and DA versus $\mathrm{p} 5$-HT correlations were registered during the post-glucose + tianeptine trial. These findings fit well with the progressive and significant reduction of $\mathrm{p} 5$-HT and increases of NA and DA values registered throughout the trial. In addition, it may explain the absence of sleep registered in this group. This fact contrasts with other one showing that the oral glucose challenge provokes sleep in normal subjects. This effect is positively correlated with the increase of circulating serotonin, always registered in them [18]. On the other hand, the maximal fall of both Ad and f5HT values interfered with the statistical assessment dealing with these parameters. These effects should be associated with the well known fact that insulin crosses the blood brain barrier and excites the A5(NA) neurons. These latter are responsible for the peripheral neural sympathetic activity which exerts hypoglycemic effects at peripheral level.

Other significant positive correlations demonstrated between NA and NA/Ad versus DBP as well as the significant negative correlation found between DA versus DBP allow us to postulate that the increases of both catecholamines depend on the enhancement of neural sympathetic activity provoked by the OGTT + tianeptine challenge.

With respect to the above and in order to understand why the association of tianeptine, a drug which reduces neural sympathetic activity [17], was able to enhance the normal neurosympathetic drive always registered throughout the OGTT should be carefully discussed.

\section{Peripheral Mechanisms}

Serotonin released from the enterochromaffin cells (ECC) during postprandial parasympathetic drives $[19,20]$ modulates both beta and alpha cells [21]. It is incorporated 
Table 1. Correlations (r) Found During the Oral Glucose Tolerance + Placebo Test Performed in 48 Normal Voluntary Humans (26 Males and 22 Females)

\begin{tabular}{|c|c|c|c|c|c|c|}
\hline & \multicolumn{6}{|c|}{ PERIODS } \\
\hline & $0 \mathrm{~min}$ & 30min & $60 \mathrm{~min}$ & $90 \mathrm{~min}$ & $120 \mathrm{~min}$ & $180 \mathrm{~min}$ \\
\hline NA vs Ad & n.s. & n.s. & n.s. & n.s. & n.s. & n.s. \\
\hline $\mathrm{NA} v s \mathrm{DA}$ & n.s. & n.s. & $.203 *$ & $.256^{*}$ & $.321 * *$ & $.293 * *$ \\
\hline Ad $v s \mathrm{DA}$ & n.s. & n.s. & n.s. & n.s. & n.s. & n.s. \\
\hline NA vs Glycemia & n.s. & n.s. & $-.221 *$ & $-.325 * *$ & $-.442 * *$ & $-.456^{* *}$ \\
\hline DA $v s$ Gycemia & n.s. & n.s. & $-.211 *$ & $-.247 *$ & $-.354 * *$ & $-.376^{* *}$ \\
\hline Ad $v s$ Glycemia & n.s. & n.s. & n.s. & n.s. & n.s. & n.s. \\
\hline NA $v s \mathrm{p}-5-\mathrm{HT}$ & n.s. & n.s. & n.s. & n.s. & n.s. & n.s. \\
\hline Ad $v s \mathrm{p}-5-\mathrm{HT}$ & n.s. & n.s. & n.s. & n.s. & n.s. & n.s. \\
\hline DA vs p-5-HT & n.s. & n.s. & n.s. & n.s. & n.s. & n.s. \\
\hline p-5-HT vs Glycemia & n.s. & n.s. & n.s. & n.s. & n.s. & n.s. \\
\hline NA vs Insulin & n.s. & n.s. & $.325^{*}$ & $.411 * *$ & $.401 * *$ & $.397 * *$ \\
\hline DA $v s$ Insulin & n.s. & n.s. & $.214^{*}$ & $.222 *$ & $.216^{*}$ & $.217^{*}$ \\
\hline Ad $v s$ Insulin & n.s. & n.s. & n.s. & n.s. & n.s. & n.s. \\
\hline p-5-HT vs Insulin & n.s. & n.s. & $-.212 *$ & -.223 & $-.231 *$ & $-.214 *$ \\
\hline NA $v s$ HR & n.s. & n.s. & n.s. & n.s. & n.s. & n.s. \\
\hline Ad $v s \mathrm{HR}$ & n.s. & n.s. & n.s. & n.s. & n.s. & n.s. \\
\hline DA $v s$ HR & n.s. & n.s. & n.s. & n.s. & n.s. & n.s. \\
\hline NA/Ad vs SBP & n.s. & n.s. & n.s. & n.s. & n.s. & n.s. \\
\hline NA/Ad $v s$ DBP & n.s. & n.s. & $.207 *$ & $.214^{*}$ & $.221 *$ & $.218^{*}$ \\
\hline $\mathrm{DA} v s \mathrm{SBP}$ & n.s. & n.s. & n.s. & n.s. & n.s. & n.s. \\
\hline DA $v s$ DBP & n.s. & n.s. & $-.213 *$ & $-.210 *$ & $-.220 *$ & $-.222 *$ \\
\hline
\end{tabular}

Levels of significance: $(*) p<0.02 ;(* *) p<0.01$. n.s. $=$ non significant. NA = noradrenaline, $\mathrm{Ad}=$ adrenaline; $\mathrm{DA}=$ dopamine; $\mathrm{p}-5$-HT $=$ platelet serotonin; HR $=$ heart rate, $\mathrm{SBP}=$ systolic blood pressure; DBP $=$ diastolic blood pressure.

into the insulin granules of the former [22,23], at which level exerts a modulatory effect [24-27]. Conversely, 5-HT facilitates the secretion of glucagon from the alpha cells into the blood stream [21,28-30]. Both serotonin and glucagon trigger the secretion of Ad from the adrenal glands and they excite hepatic glucogenolysis which counteract the hypoglycemic effect of the insulin released from beta cells. Thus, the overwhelming insulinogenic effect triggered by the addition of tianeptine to an oral glucose load should annul the alpha-cell plus adrenal gland cascade.

Findings showed that serotonin loaded into the beta cells localizes to the insulin secretory granules and is additionally co-released with it $[26,27]$. These authors demonstrated that there is little exocytotic activity of insulin +5 -HT at the basal glucose level, but increasing the sugar concentration results in increased insulin release from perfused beta cells. Furthermore, Deeney et al. [26] concluded that serotonin might be considered as a marker for insulin release. Thus, taking into account that tianeptine enhances the uptake of 5HT by both neurons and platelets, it might also facilitate this mechanism at the beta cell level, which minimized the insulin release from the latter. Thus, this modulatory mechanism would be favored by the drug.

In addition to the above and taking into account that plasma serotonin excites both alpha-cells and adrenal glands directly [21,29,31-34], the disappearance of those hyperglycemic factors would favor the predominance of the insulinogenic effect registered in this study. This phenomenon should be associated with other findings showing that adrenalectomy is able to interfere with the glucagon induced plasma glucose rises provoked by intravenous administration of 5-HT [35]. Finally, the fact that methysergide, a 5-HT antagonist, can prevent the glucagon effects, affords additional support to the postulation that serotonin was the responsible factor for the above phenomenon by acting at the islet cells directly $[28,36]$.

The above comments are reinforced by others showing that intraperitoneally injected serotonin increases glucagon plus glucose and reduces insulin plasma levels; thus, the annulment of these effects triggered by the addition of tianeptine to the oral glucose load should be attributed to the interference by the drug, not only at CNS, but also at the peripheral level. In addition, the fact that adrenodemedullation prevented both the glucose rise and the insulin fall, but not the glucagon rise, indicated that the effects at the beta-cell level were mediated by the adrenaline released from the adrenal glands [21,29,31,33,34,37,38].

The peripheral neural sympathetic over-activity registered during the glucose plus tianeptine trial fits well with the minimization of the parasympathetic drive which excites the ECC system, as inferred by the lowering of p5HT circulating levels observed throughout the test. This parasympathetic mechanism is bridled by sympathetic 
Table 2. Correlations (r) Found During the Oral Glucose Tolerance + Tianeptine Test Performed in 48 Normal Voluntary Humans (26 Males and 22 Females)

\begin{tabular}{|c|c|c|c|c|c|c|}
\hline & \multicolumn{6}{|c|}{ PERIODS } \\
\hline NA $v s$ DA & n.s. & n.s. & $.368 * *$ & $.377 * *$ & $.405^{* *}$ & $.426 * *$ \\
\hline Ad $v s \mathrm{DA}$ & n.s. & n.s. & n.s. & n.s. & n.s. & n.s. \\
\hline DA vs Glycemia & n.s. & n.s. & $-.332 *$ & $-.365^{*}$ & $-.411 * *$ & $-.395 * *$ \\
\hline Ad vs Glycemia & n.s. & n.s. & n.s. & n.s. & n.s. & n.s. \\
\hline NA $v s \mathrm{p} 5-\mathrm{HT}$ & n.s. & n.s. & $-.244 *$ & $-.332 *$ & $-.326^{*}$ & $-.299 *$ \\
\hline Ad $v s \mathrm{p} 5-\mathrm{HT}$ & n.s. & n.s. & n.s. & n.s. & n.s. & n.s. \\
\hline DA $v s$ Insulin & n.s. & n.s. & $.199 *$ & $.218^{*}$ & $.235^{*}$ & $.239 *$ \\
\hline Ad $v s$ Insulin & n.s. & n.s. & n.s. & n.s. & n.s. & n.s. \\
\hline p-5-HT vs Insulin & n.s. & n.s. & $-.368 * *$ & $-.387 * *$ & $-.359 * *$ & $-.371 * *$ \\
\hline NA $v s \mathrm{HR}$ & n.s. & n.s. & n.s. & n.s. & n.s. & n.s. \\
\hline Ad $v s \mathrm{HR}$ & n.s. & n.s. & n.s. & n.s. & n.s. & n.s. \\
\hline DA $v s \mathrm{HR}$ & n.s. & n.s. & n.s. & n.s. & n.s. & n.s. \\
\hline $\mathrm{NA} / \mathrm{Ad} v s \mathrm{SBP}$ & n.s. & n.s. & n.s. & n.s. & n.s. & n.s. \\
\hline $\mathrm{NA} / \mathrm{Ad} v s \mathrm{DBP}$ & n.s. & n.s. & $.232 *$ & $.229 *$ & $.239 *$ & $.241^{*}$ \\
\hline
\end{tabular}

Levels of significance: $(*) p<0.05 ;(* *) p<0.02$. n.s. $=$ non significant. $\mathrm{NA}=$ noradrenaline, $\mathrm{Ad}=$ adrenaline; $\mathrm{DA}=$ dopamine; $\mathrm{p} 5$-HT $=$ platelet serotonin; HR = heart rate, $\mathrm{SBP}=$ systolic blood pressure; $\mathrm{DBP}=$ diastolic blood pressure.

nerves. With respect to this, it should be known that f5-HT but not p5-HT is able to excite the medullary area postrema (AP), which sends modulatory axons to both vagal and adrenergic medullary nuclei, responsible for the parasympathetic and adrenal sympathetic peripheral activities, respectively [20,39-41]. These activities were minimized throughout the OGTT + tianeptine test because of the fall of f5-HT. With respect to this, it should be known that both circulating Ad and ACh are able to increase f5-HT, the former because it triggers platelet aggregation, whereas the latter throughout the interference with the platelet uptake of serotonin [42].

In short, the annulment of both adrenal sympathetic and parasympathetic activities registered in this study should be associated to the suppression of the stimulatory drives by f5HT at the area postrema, which sends excitatory and inhibitory axons to the medullary vagal complex and the C1(Ad) nuclei, respectively. The latter resulted in the minimization of the peripheral adrenal sympathetic activity registered in this study $[43,44]$. With respect to the above, it should be known that the $\mathrm{Cl}(\mathrm{Ad})$ nuclei interchanges inhibitory axons with A5(NA) pontomedullary nucleus, responsible for neural sympathetic activity $[45,46]$ thus, the
Table 3. Changes in Systolic Blood Pressure (SBP), Diastolic Blood Pressure (DBP) and Heart Rate (HR) Induced in 48 Normal Voluntary Humans (26 Males and 22 Females) when One OGTT Plus Placebo and One OGTT Plus Tianeptine Tests were Carried Out 2 Weeks Apart

\begin{tabular}{|c|c|c|c|c|}
\hline \multirow{2}{*}{} & \multicolumn{2}{|c|}{ OGTT + Placebo Test } & \multirow{2}{*}{ OGTT + Tianeptine Test } \\
\cline { 2 - 5 } & $\mathbf{0 m i n}$ & $\mathbf{1 8 0}$ min & 0min & 180min \\
\hline \hline HR (beats/min) & $71 \pm 5$ & $66 \pm 7 *$ & $73 \pm 7$ & $65 \pm 8^{* *}$ \\
\hline SBP (mmHg) & $127 \pm 8$ & $122 \pm 3$ & $127 \pm 8$ & $124 \pm 7$ \\
\hline DBP (mm Hg) & $73 \pm 5$ & $76 \pm 4 *$ & $71 \pm 6$ & $88 \pm 4^{* *}$ \\
\hline
\end{tabular}

disappearance of the activity of the former, triggered by tianeptine minimized the peripheral adrenal sympathetic drive and favored the absolute predominance of the neural sympathetic activity registered in the present study. With respect to the latter, exhaustive evidence has demonstrated that insulin crosses the blood brain barrier and excites the A5(NA) nucleus responsible for the activity of sympathetic nerves $[9,47-$ 49]. 
It is well known that at CNS level, tianeptine triggers the absolute disappearance of 5-HT from synaptic clefts. With respect to this, it should be known that the $\mathrm{Cl}(\mathrm{Ad})$ medullary nuclei responsible for the adrenal glands activity [44] receive excitatory 5-HT axons from the dorsal raphe DR(5-HT) nucleus $[50,51]$ and also from the medullary serotonergic nuclei: raphe magnus, raphe obscurus and raphe pallidus [52]. Thus, the drug should interfere with these excitatory drives to the $\mathrm{Cl}(\mathrm{Ad})$ nuclei. In addition, exhaustive evidence has demonstrated that serotonin released at the hypothalamic level is responsible for the neuroendocrine cascade which excites the adrenal glands secretion thus; this excitatory adrenergic drive should also be suppressed by tianeptine [51].

In summary, considering that $5-\mathrm{HT}$ is taken up by serotonergic axons, platelets and beta cells, tianeptine, a drug which enhances this mechanism, should eliminate this serotonergic hyperglycemic effect, which interfere with the insulin secretion. This postulation fits well with the ability of drugs that interfere rather than enhance 5-HT uptake (like doxepin, sertraline, paroxetine or fluvoxamine) to counteract hyper-insulinism + hypoglycemia syndrome [16,53].

We should also comment the DA plasma rises registered in this study. These findings are in line with our preliminary research studies showing that the diabetogenic effect triggered by captivity and/or sulpiride was positively and negatively correlated with 5-HT and DA blood levels, respectively [11-13]. This circulating neurotransmitters profile contrasts with the effects reported in this study. Furthermore, the significant NA versus DA positive correlations shown in the present research work indicates that both catecholamines have arisen from the sympathetic nerves. Finally, these findings agree with others showing that DA plays a direct excitatory role at the beta-cells level [54].

At the CNS level, findings showed that both insulin and glucagon crosses the blood brain barrier and excite the A5(NA) [55] and the $\mathrm{Cl}(\mathrm{Ad})$ [56] pontomedullary nuclei responsible for the neural and adrenal sympathetic activities, respectively thus, the predominance of the former mechanism registered in the present study is in accordance with the above.

Summarizing, both insulin and glucagon crosses the blood brain barrier and excites the $\mathrm{Cl}(\mathrm{Ad})$ medullary nuclei and the A5(NA), respectively. Both nuclei interchange inhibitory axons $[9,45]$. Predominance of the former would result in neural sympathetic activity plus hyperinsulinism + hypoglycemia whereas, the opposite peripheral profile depends on the overactivity of the $\mathrm{Cl}(\mathrm{Ad})$ nuclei (adrenal sympathetic excitation plus hyperglycemia). This catecholaminergic binomial CNS axis is modulated by the CNS serotonergic axons arising from the pontine dorsal raphe (DR), median raphe (MR) nuclei and the medullary serotonergic system which includes the raphe magnus, raphe obscurus and raphe pallidus nuclei. A great bulk of quoted evidence has demonstrated that whereas the $\mathrm{DR}(5-\mathrm{HT})$ is positively correlated with adrenal sympathetic activity, the MR(5-HT) potentiates the neural sympathetic branch [52]. The enhancement of neural sympathetic activity + hyperinsulinism registered in the present study strongly suggests that the drug suppressed the activity of the DR $(5-\mathrm{HT})+\mathrm{Cl}(\mathrm{Ad})$ axis which favored the disinhibition of the A5(NA) plus the MR(5-HT) binomial [57]. Thus, the potentiation by tianeptine of the normal glucose-induced neural sympathetic activity should be added to the minimization of both the parasympathetic plus the adrenal sympathetic activities which redound in the absolute predominance of the neural sympathetic system.

\section{CONCLUSIONS}

Type-2 diabetes depends on the unbalance between insulin and glucagon, at peripheral level. However, considering that both hormones cross the blood brain barrier and excite the $\mathrm{C} 1$ (Ad) and the A5(NA) nuclei, respectively, we postulated that an adequate neuropharmacological manipulation at the CNS level would facilitate the predominance of the latter over the former favoring the hypoglycemic effect of the insulin. In accordance with this hypothesis, we were able to demonstrate that tianeptine, a drug which reduces serotonin levels at both plasma and synaptic clefts, was able to enhance plasma insulin throughout the oral glucose tolerance test in normal subjects. The facts showing that the plasma NA rises and blood serotonin decreases showed significant positive and negative correlations with insulin levels, respectively, allowed us to postulate that tianeptine should be a powerful neuropharmacological drug to treat diabetic patients.

\section{REFERENCES}

[1] Lechin F, Coll-Garcia E, van der Dijs B, Peña F, Bentolila A, Rivas C. The effect of serotonin (5-HT) on insulin secretion. Acta Physiol Latinoamer 1975; 25: 339-46.

[2] Lechin F. Secretina y potasio sérico. GEN 1963; 17: 347-50.

[3] Lechin F. Intestinal hormones and plasma insulin. Lancet 1966; ii: $35-6$.

[4] Lechin F, Coll-Garcia E, van der Dijs B. Efectos de la serotonina (5HT) sobre la secreción de insulina por islotes aislados incubados in vitro. Acta Cient Ven 1973; 24: 32-40.

[5] Lechin F, Coll-Garcia E, van der Dijs B. Efectos de la administración intraportal de serotonina (5-HT), sobre los niveles de glucosa e insulina inmuno-reactiva (IRI), de la vena pancreato-duodenal del perro. Acta Cient Ven 1973; 24: 19-24.

[6] Jacoby JH, Bryce GF. The acute pharmacologic effects of serotonin on the release of insulin and glucagon in the intact rat. Arch Int Pharmacodyn Ther 1978; 235: 254-70.

[7] Lechin F, van der Dijs B, Lechin M, et al. Plasma neurotransmitters throughout an oral glucose tolerance test in essential hypertension. Clin Exp Hypertens 1993; 15: 209-40.

[8] Chisholm DJ, Young JD, Lazarus L. The gastrointestinal stimulus to insulin release. I. Secretin. J Clin Invest 1969; 48: 1453-60.

[9] Lechin F, van der Dijs B. Central nervous system (CNS) circuitry involved in the hyperinsulinism syndrome. Neuroendocrinology 2006; 84: 222-34.

[10] Lechin F, Coll-Garcia E, van der Dijs B, Bentolila A, Peña F, Rivas C. Effects of captivity on glucose tolerance in dogs. Experientia 1979; 35: 876-8.

[11] Lechin F, Coll-Garcia E, van der Dijs B, Bentolila A, Peña F, Rivas C. The effects of dopaminergic blocking agents on the glucose tolerance test in six humans and six dogs. Experientia 1979; 35: 8868 .

[12] Lechin F, van der Dijs B. Haloperidol and insulin release. Diabetologia 1981; 20: 78-9.

[13] Lechin F, van der Dijs B. Intestinal pharmacomanometry and glucose tolerance: evidence for two antagonistic dopaminergic mechanisms in the human. Biol Psychiatry 1981; 16: 969-86.

[14] Lechin F, van der Dijs B. Enterohormonas, insulina y glucagon. (Review) Acta Gastroenterol Latinoamer 1978; 8: 27-8.

[15] Lechin F, van der Dijs B. Glucose tolerance, non-nutrient drink and gastrointestinal hormones. Gastroenterology 1981; 80: 216-7.

[16] Lechin F, van der Dijs B, Lechin A, et al. Doxepin therapy for postprandial symptomatic hypoglycemic patients: neurochemical, hormonal and metabolic disturbances. Clin Sci 1991; 80: 373-84.

[17] Lechin F, van der Dijs B, Hernandez G, Orozco B, Rodríguez S, Baez S. Acute effects of tianeptine on circulating neurotransmitters and cardiovascular parameters. Prog Neuropsychopharmacol Biol Psychiatry 2006; 30: 214-22. 
[18] Lechin F, van der Dijs B, Lechin M, et al. Effects of an oral glucose load on plasma neurotransmitters in humans: involvement of REM sleep? Neuropsychobiology 1992; 26: 4-11.

[19] Tobe T, Izumikawa F, Sano M, Tanaka C. In: Fujita T, Ed. Endocrine Gut-Pancreas. Amsterdam: Elsevier 1976; pp. 371-80.

[20] Schwörer H, Racké K, Kilbinger H. Cholinergic modulation of the release of 5-hydroxytryptamine from the guinea pig ileum. Naunyn Schmiedeberg's Arch Pharmacol 1987; 336: 127-32.

[21] Adeghate E, Ponery AS, Pallot D, Parvez SH, Singh J. Distribution of serotonin and its effect on insulin and glucagon secretion in normal and diabetic pancreatic tissues in rat. Neuro Endocrinol Lett 1999; 20: 315-22.

[22] Gylfe E. Serotonin as marker for the secretory granules in the pancreatic beta-cell. Acta Physiol Scand Suppl 1977; 452: 125-8.

[23] Gylfe E. Association between 5-hydroxytryptamine release and insulin secretion. J Endocrinol 1978; 78: 239-48.

[24] Zawalich WS, Tesz GJ, Zawalich KC. Are 5-hydroxytryptaminepreloaded beta-cells an appropriate physiologic model system for establishing that insulin stimulates insulin secretion? J Biol Chem 2001; 276(40): 37120-23.

[25] Zawalich WS, Tesz GJ, Zawalich KC. Effects of prior 5hydroxytryptamine exposure on rat islet insulin secretory and phospholipase C responses. Endocrine 2004; 23: 11-6.

[26] Deeney JT, Bränström R, Corkey BE, Larsson O, Berggren PO. 3Hserotonin as a marker of oscillatory insulin secretion in clonal betacells (INS-1). FEBS Lett 2007; 581(21): 4080-4.

[27] Baldeiras IE, Santos RM, Rosário LM. Protein kinase C isoform specificity of cholinergic potentiation of glucose-induced pulsatile 5$\mathrm{HT} /$ insulin release from mouse pancreatic islets. Biol Res 2006; 39(3): 531-9.

[28] Marco J, Hedo JA, Villanueva ML. Inhibition of glucagon release by serotonin in mouse pancreatic islets. Diabetologia 1977; 13(6): 585-8.

[29] Barseghian G, Lev-Ran A, Hwang D, Josefsberg Z, Tomkinson C. Fenfluramine inhibits insulin secretion and potentiates glucagon release by the perfused rat pancreas. Eur J Pharmacol 1983; 96: 53-9.

[30] Chaouloff F, Gunn SH, Young JB. Central 5-hydroxytryptamine2 receptors are involved in the adrenal catecholamine-releasing and hyperglycemic effects of the 5-hydroxytryptamine indirect agonist dfenfluramine in the conscious rat. J Pharmacol Exp Ther 1992; 260: 1008-16.

[31] Carvalho F, Barros D, Silva J, et al. Hyperglycemia induced by pharmacological activation of central serotonergic pathways depends on the functional integrity of brain CRH system and 5-HT3 receptors. Horm Metab Res 2005; 37: 482-8.

[32] de Leiva A, Tanenberg RJ, Anderson G, Greenberg B, Senske B, Goetz FC. Serotoninergic activation and inhibition: effects on carbohydrate tolerance and plasma insulin and glucagon. Metabolism 1978; 27: 511-20.

[33] Holst JJ, Grønholt R, Schaffalitzky de Muckadell OB, Fahrenkrug J. Nervous control of pancreatic endocrine secretion in pigs. I. Insulin and glucagon responses to electrical stimulation of the vagus nerves. Acta Physiol Scand 1981; 111: 1-7.

[34] Hussain K, Bryan J, Christesen HT, Brusgaard K, Aguilar-Bryan L. Serum glucagon counterregulatory hormonal response to hypoglycemia is blunted in congenital hyperinsulinism. Diabetes 2005; 54(10): 2946-51.

[35] O'Donovan D, Feinle C, Tonkin A, Horowitz M, Jones KL. Postprandial hypotension in response to duodenal glucose delivery in healthy older subjects. J Physiol 2002; 540: 673-9.

[36] Yamada J, Sugimoto Y, Yoshikawa T, Kimura I, Horisaka K. The involvement of the peripheral 5-HT2A receptor in peripherally administered serotonin-induced hyperglycemia in rats. Life Sci 1995; 57(8): 819-25.

[37] Cryer PE. Glucagon and hyperglycaemia in diabetes. Clin Sci 2008; 114: 589-90.

[38] Ravier MA, Rutter GA. Glucose or insulin, but not zinc ions, inhibit glucagon secretion from mouse pancreatic alpha-cells. Diabetes 2005; 54: 1789-97.
[39] Zhu JX, Zhu XY, Owyang C, Li Y. Intestinal serotonin acts as a paracrine substance to mediate vagal signal transmission evoked by luminal factors in the rat. J Physiol 2001; 530: 431-42.

[40] Ahlman H, DeMagistris L, Zinner M, Jaffe BM. Release of immunoreactive serotonin into the lumen of the feline gut in response to vagal nerve stimulation. Science $1981 ; 213(4513)$ : 1254-5.

[41] Orer HS, Gebber GL, Barman SM. Role of serotonergic input to the ventrolateral medulla in expression of the $10-\mathrm{Hz}$ sympathetic nerve rhythm. Am J Physiol Regul Integr Comp Physiol 2008; 294: R143544.

[42] Rausch JL, Janowsky DS, Risch SC, Huey LY. Physostigmine effects on serotonin uptake in human blood platelets. Eur J Pharmacol 1985; 109: 91-6.

[43] Reynolds DJ, Leslie RA, Grahame-Smith DG, Harvey JM Localization of 5-HT3 receptor binding sites in human dorsal vagal complex. Eur J Pharmacol 1989; 174: 127-30.

[44] Urbanski RW, Sapru HN. Evidence for a sympathoexcitatory pathway from the nucleus tractus solitarii to the ventrolateral medullary pressor area. J Auton Nerv Syst 1988; 23: 161-74.

[45] Li YW, Wesselingh SL, Blessing WW. Projections from rabbit caudal medulla to $\mathrm{C} 1$ and A5 sympathetic premotor neurons, demonstrated with phaseolus leucoagglutinin and herpes simplex virus. J Comp Neurol 1992; 317: 379-95.

[46] Byrum CE, Guyenet PG. Afferent and efferent connections of the A5 noradrenergic cell group in the rat. J Comp Neurol 1987; 261: 52942.

[47] Rowe JW, Young JB, Minaker KL, Stevens AL, Pallotta J, Landsberg L. Effect of insulin and glucose infusions on sympathetic nervous system activity in normal man. Diabetes 1981; 30: 219-25.

[48] Christensen NJ, Hilsted J, Egger M, Teuscher A, Frier BM, Hepburn DA. Plasma noradrenaline, human insulin, and hypoglycaemia. Lancet 1989; 334(8674): 1268-9.

[49] Lechin F, van der Dijs B. Central nervous system circuitry and peripheral neural sympathetic activity responsible for essential hypertension. Curr Neurovasc Res 2006; 3: 307-25.

[50] Peyron C, Luppi PH, Fort P, Rampon C, Jouvet M. Lower brainstem catecholamine afferents to the rat dorsal raphe nucleus. J Comp Neurol 1996; 364: 402-13.

[51] Underwood MD, Arango V, Bakalian MJ, Ruggiero DA, Mann JJ. Dorsal raphe nucleus serotonergic neurons innervate the rostral ventrolateral medulla in rat. Brain Res 1999; 824: 45-55.

[52] Lechin F, van der Dijs B, Hernandez-Adrian G. Dorsal Raphe (DR) vs Median Raphe (MR) serotonergic antagonism. Anatomical, physiological, behavioral, neuroendocrinological, neuropharmacological and clinical evidences: Relevance for neuropharmacological therapy. Prog Neuro-Psychopharmacol Biol Psychiatry 2006; 30: 565-85.

[53] Briscoe VJ, Ertl AC, Tate DB, Davis SN. Effects of the selective serotonin reuptake inhibitor, fluoxetine, on counterregulatory responses to hypoglycemia in individuals with type 1 diabetes. Diabetes 2008; 57(12): 3315-22.

[54] Uvnäs-Moberg K, Ahlenius S, Alster P, Hillegaart V. Effects of selective serotonin and dopamine agonists on plasma levels of glucose, insulin and glucagon in the rat. Neuroendocrinology 1996; 63: 269-74

[55] Fisher SJ, Brüning JC, Lannon S, Kahn CR. Insulin signaling in the central nervous system is critical for the normal sympathoadrenal response to hypoglycemia. Diabetes 2005; 54: 1447-51.

[56] Abdelmelek H, Fechtali T, Filali-Zegzouti Y, et al. Responsiveness of plasma catecholamines to intracerebroventricular injection of glucagon in Muscovy ducklings. J Neural Transm 2001; 108: 793801 .

[57] Lechin F, van der Dijs B. In: Maiese K. Ed. Neurovascular medicine: pursuing cellular longevity for healthy aging. London, Oxford: University Press 2008; pp. 101-52.

This is an open access article licensed under the terms of the Creative Commons Attribution Non-Commercial License (http://creativecommons.org/licenses/by$\mathrm{nc} / 3.0 /$ ) which permits unrestricted, non-commercial use, distribution and reproduction in any medium, provided the work is properly cited. 